\title{
Laparoscopic tubal surgery for ectopic pregnancy: trainees' perspective in the $\mathrm{UK}$
}

\author{
Rasiah Bharathan $\cdot$ Sarah Merritt $\cdot$ Hasib Ahmed
}

Received: 31 March 2011 /Accepted: 6 August 2011 /Published online: 3 September 2011

(C) Springer-Verlag 2011

\begin{abstract}
Ectopic pregnancies (EP) account for approximately $1 \%$ of all pregnancies. Surgical management of such patients should be accomplished through the laparoscopic route. Presently, available data from national studies suggest that only a minority of women benefit from such an approach. Regional studies and single institution reports suggest that trainee involvement in these procedures vary widely. Competency in laparoscopic surgery for EP is a mandatory requirement for independent practice in the UK. In a recent survey of UK trainees of all grades in obstetrics and gynaecology, 53.4\% of trainees reported that they were trained or being trained in such procedures. This study examines the perspectives of the trainees. We performed a national questionnaire survey of intermediate- and advanced-level trainees in the UK During a 12 -month period, $52 \%$ of trainees had performed at least one
\end{abstract}

\footnotetext{
R. Bharathan $(\bowtie)$

Nuffield Department of Obstetrics \& Gynaecology,

John Radcliffe Hospital,

Headley Way,

Oxford OX3 9DU, UK

e-mail: r.bharathan@doctors.org.uk

S. Merritt

Department of Obstetrics \& Gynaecology, St. Thomas' Hospital, Westminster Bridge Road,

London SE1 7EH, UK

H. Ahmed

Department of Obstetrics \& Gynaecology,

Medway Maritime Hospital,

Gillingham, Kent ME7 5NY, UK
}

procedure independently; $80 \%$ of trainees performed most of the procedure on at least one occasion. The satisfaction with training was rated as 3 on a five-point Likert scale. Thirty percent of the trainees had access to a laparoscopy simulator. We found a high level of trainee engagement with laparoscopic tubal surgery. The intensity of experience is likely inadequate to satisfy the learning curve. A holistic approach s required to ensure surgical competence.

Keywords Training - Laparoscopy $\cdot$ Ectopic pregnancy

\section{Background}

Ectopic pregnancies (EP) account for approximately $1 \%$ of all pregnancies, and $95 \%$ of these are located in the fallopian tube [1]. Optimal surgical management, based on the evidence of three randomised controlled trials, is achieved through the laparoscopic access [2-4]. In haemodynamically stable patients, current UK guidelines recommend laparoscopic surgery [5]. Presently, available data from two national studies suggest that only $27 \%$ and $35 \%$ of women were managed by laparoscopic surgery even though $90 \%$ of gynaecologists reported that if resources were available, laparoscopic approach could be adopted $[6,7]$. In a recent regional study, $84 \%$ of patients were managed via laparoscopic surgery [8]. An earlier regional study revealed that $37 \%$ of trainees performed laparoscopic surgery for EP, but more recently, an urban single institution experience revealed that $53 \%$ of procedures were performed by trainees $[9,10]$. With structured 
enthusiastic effort, over $90 \%$ of cases can be managed through laparoscopic route [11]. Competency in laparoscopic tubal surgery for EP is a mandatory requirement for the completion of training. Factors that have impeded rapid uptake and training include reduced exposure following the European Working Time Directive (EWTD), lack of appropriate trainers, theatre resources and implications of clinical governance. With ever wider provision of specialised early pregnancy assessment service and the subsequent conservative or medical management of patients with tubal pregnancy, the opportunities for training in the surgical management of such patients are further reduced. In a recent survey of UK trainees of all grades in obstetrics and gynaecology, $53.4 \%$ of trainees reported that they were trained or being trained to manage ectopic pregnancies laparoscopically; however, $47.3 \%$ said they had not performed surgery for ectopic pregnancy in the preceding 12 months [12]. In the same report, the proportion of trainees who said that supervision in theatre for all procedures was good or very good was $57 \%$; this has remained stable since the first such survey in 1995. Since laparoscopic surgery for EP is a common procedure, a study of this from a trainee's perspective could be informative regarding the management of training.

\begin{abstract}
Aims
Our questionnaire study aims to provide a measure of the surgical experience gained by the trainees and their perception of the quality of training across the specialty with regard to laparoscopic management of EP.
\end{abstract}

\section{Materials and methods}

With the approval of the Royal College of Obstetricians and Gynaecologists (RCOG) Honorary Secretary, a questionnaire was posted to specialist registrars or specialty trainees who had completed basic training for at least 2 years and were in the process of obtaining core (Specialty Trainee 3-5) or advanced level (Specialty Trainee 6-7) training within the UK in 2009. Each trainee was sent a cover letter, questionnaire (see Appendix) and a stamped addressed envelope for return. The postal communication was handled by the hospital clinical audit department. A reminder letter was not sent to non- responders; this preserves anonymity, and although a reminder may improve the response rate, it is unlikely to affect the overall findings. The questionnaire requested information from trainees regarding their grade, length of training, the extent and depth of their involvement in laparoscopic salpingectomy during the preceding 12 months, method of tubal salpingectomy, practice of salpingotomy, attendance at a laparoscopy course and availability of a laparoscopic simulator. In addition, our study illustrates the self-assessed competency level with regard to laparoscopic salpingectomy. In addition a fivepoint Likert scale, a widely used validated subjective assessment tool, was used to gauge the trainees' level of satisfaction with training and whether they anticipated attaining competency in laparoscopic tubal surgery prior to completion of training. On this scale, a score of 1 indicates a negative response and 5 indicates a positive response.

\section{Findings}

A total of 645 questionnaires were posted to registrar level trainees in obstetrics and gynaecology across the UK. Two hundred four responses were received (31.6\%). Thirteen of the respondents had been appointed as consultants, and therefore, these responses were excluded from the analysis. Fourteen $(7.3 \%)$ respondents were at specialist trainee (ST) level 3, $29(15.2 \%)$ at ST4, 38 $(19.9 \%)$ at ST5, $44(23 \%)$ at ST6 and $56(29.3 \%)$ were at ST7. A further ten $(5.2 \%)$ were categorised as other as a grade was not specified, and their response is included in the analysis.

During the preceding 12 months, the median number of laparoscopic procedures for tubal ectopic pregnancies where a trainee was involved was four (interquartile range (IQR), 2-8). During the same period, the median number of procedures where the trainee performed the procedure at level 4 competency was three (IQR, 1-7). One hundred trainees had performed at least one laparoscopic tubal surgery at level 5 competence. Similarly, 54 trainees performed at least one procedure at level 4 competency, 26 trainees at level 3 and further ten trainees at level 2. One trainee did not respond to this question.

In terms of tubal preservation, $82(43 \%)$ trainees reported that they performed salpingotomy when appropriate, whilst $98(51 \%)$ did not perform such a procedure; 11 
(6\%) did not provide a response to that question. With regard to the method of excising the fallopian tube, 81 $(42 \%)$ trainees reported that they preferred endoloop ligature and excision, $96(50 \%)$ preferred diathermy excision, $6(3 \%)$ used both of these techniques and the remaining $8(4 \%)$ did not respond.

Ninety (47\%) trainees had attended a level 2 RCOGrecognised or equivalent laparoscopy course within the preceding 2 years; the remaining 101 trainees had not attended such a course during this timeline. Fifty-seven $(30 \%)$ trainees reported that they had access to a laparoscopic simulator at their place of work; the remaining134 $(70 \%)$ trainees did not have such facility.

Figure 1 illustrates Likert scale responses to questions on whether the trainee anticipates reaching level 5 competence at completion of their training and secondly responses with regard to their level of satisfaction of training provided with regard to laparoscopic tubal surgery. Figure 1 demonstrates that $96(50 \%)$ trainees felt it very likely that they would attain competence at level 5 prior to completion of training. However, the level of satisfaction with training is more uniformly distributed. The median Likert score for satisfaction with training was 2 (IQR, 1-3) for the junior group and 4 (IQR, 2-5) for the senior group in our study cohort. The median Likert score regarding their anticipation of attaining level 5 competency by completion of training was 4 (3-5) amongst the junior group and 5 (4-5) for the more senior group.

\section{Free comments from the survey}

In summary, comments suggested that university hospitals are more likely to provide a 'satisfactory' training. Additional

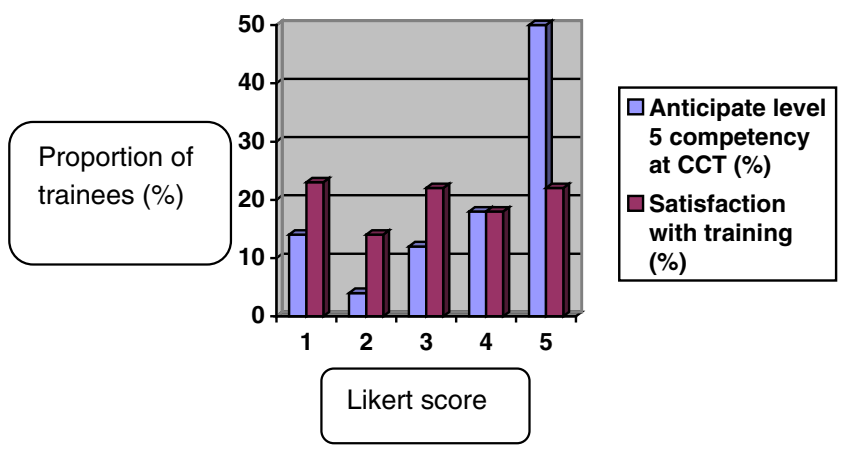

Fig. 1 Likert scale scores and their percentage distribution factors which are perceived to influence the quality of laparoscopic training include rota arrangements which tend to favour the most senior trainees with respect to gynaecologic surgery, commitment from trainers and fluency of trainers in performing such procedures. Many trainees cited out of programme training in minimal access surgery as the most reliable solution.

\section{Discussion}

Clinical training, surgical education, workforce planning, patient safety and clinical governance are intertwined issues which concern all stakeholders. Composition, quality and delivery of training seem to preoccupy trainees as well as trainers. These issues are increasingly brought into focus as the duration and intensity of exposure of the trainees to clinical practice have declined. Legislation such as the EWTD and importantly the changing nature of gynaecological practice has had a major impact on training. In the UK presently, the emphasis on training is focused on improving the delivery of acute care such as intrapartum care and early pregnancy complications. Appropriate management of ectopic pregnancy is an important element of this care. This survey provides a 'snapshot' of trainees' perspective with regard to laparoscopic management of EP.

Overall response rate was $31.6 \%$, and effective response rate was $29.6 \%$. In this group, $42.4 \%$ of the respondents were within the junior registrar ranks, and $52.3 \%$ were senior registrars; the remaining 5.2\% were non-career grade doctors who effectively function as registrars in the provision of service. During the preceding 12 months, $15(7.9 \%)$ trainees said they had not been involved in a single procedure. The median number of procedures that a trainee was involved in was 4 , and that where they performed at least most of the procedure was 3. During the same period, 147 (77\%) trainees had performed most or all of at least one procedure under supervision. The RCOG survey had 1,001 respondents, which equated to about $66 \%$ of all trainees in the UK. Among this group of respondents, $30 \%$ were in 'basic' training and a further $10 \%$ represented a miscellaneous group of trainees who were lecturers, subspecialty trainees and research fellows; these subgroups were not targeted by our study as they 
would not have been suitable subjects. The target group of our study corresponds to the remaining $60 \%$ of that study. The RCOG trainees' survey reported that $47.3 \%$ of trainees had not performed any procedure during a 12 -month period [12]. This discrepancy could be explained by the differing target groups of the surveys and potentially the phrasing of the question; in our survey, a graded response was possible with regard to the level of involvement, which was not the case with the RCOG survey. Further, amongst our group, 180 (94.2\%) trainees had performed some component of at least one procedure. This lends weight to the finding that $90 \%$ of units felt that they could offer laparoscopic surgery for EP if adequate resources were available [7].

With regard to conservation of the tube, $51 \%$ of the respondents do not perform salpingotomy. A simulatorbased assessment of salpingectomy revealed a learning curve in terms of time taken per procedure to reach a plateau to be up to 6 procedures for experts, 21 for intermediates and 27 for novices [13]. Although there are no similar data available for salpingotomy, but due to the need for a broader range of laparoscopic skills, it is our opinion that the likely learning curve for salpingotomy will be steeper. This will have implications for training and provision of such service by a generalist on an ad hoc basis. Conservation of the tube assumes clinical significance for psychological reasons or if the contralateral tube is diseased.

In this survey, $50 \%$ of the trainees preferred diathermy excision, whilst $42 \%$ preferred endoloop; the remainder used both techniques. A randomised controlled trial of salpingectomy by means of endoloop versus electrocautery demonstrated that with endoloop, operation takes shorter, a patient has less pain and lesser total analgesia requirement by day 7 [14]. Perhaps, trainees could be encouraged to utilise a technique which benefits the woman and optimises the use of operating theatre time. It is worth noting that Endoloop technique leads to a partial salpingectomy, whilst electrocautery offers the opportunity to perform total salpingectomy; tubal stump ectopic pregnancy could indeed be an extremely rare complication.

The RCOG-approved intermediate-level laparoscopy courses provide theoretical as well as practical teaching. There is some evidence that such courses can enable development and retention of skills $[15,16]$. Longitudinal impact and potential need for reiteration have not been studied over a significant period, but at least annual verification would be necessary [17]. In our survey, only $47 \%$ of registrar level trainees had attended such a course within a 2-year period. Following instruction in laparoscopic surgery, consolidation in the form of practice would be required. It is well established in the literature that surgical complications decline with progression along the learning curve; this is indeed the case in laparoscopic surgery, where most problems tend to occur during the early learning phase $[18,19]$. Both for logistical advantage and in the interest of patient safety, trainees should familiarise themselves with the instruments and make grounds on the learning curve prior to the clinical encounter of an acutely ill patient. In this respect, evidence from randomised clinical trials demonstrates that skills learnt with the aid of a simulator can be successfully transferred to the operating theatre [20-22]. In this study, 57 (30\%) trainees reported having access to a simulator facility. This confirms the similar finding in a regional study regarding access to a simulator [23]. The same study revealed that although $81 \%$ of the respondents felt simulator training was essential in improving laparoscopic skills, trainees did not make adequate use of facilities where they existed [23].

So, how can we improve the training, performance and satisfaction of the trainees? The concept of surgical competence frames components in surgical practice which can optimise the performance (Fig. 2), namely psychomotor skills, communication skills, knowledge base and evaluation and continuing development. This could be a useful framework both for the trainer and the trainee since it provides a scaffolding for surgical education. A better understanding of the environment, needs of the health care system and the methods of training and assessment will help the trainees to manage their own expectation and progress.

Psychomotor skills can be learnt through courses and refined through simulation practice and later in the operating theatre. One option that might increase usage of simulators is if they are made available at a regional level with nominated supervisors for dedicated sessions. RCOG is currently examining the role of simulators in formal training. A regional study from the UK revealed that all hospitals had the necessary laparoscopic equipment; so, simulator training could be a meaningful adjunct in augmenting training across the board [24]. The potential value of a simulator in such training is 


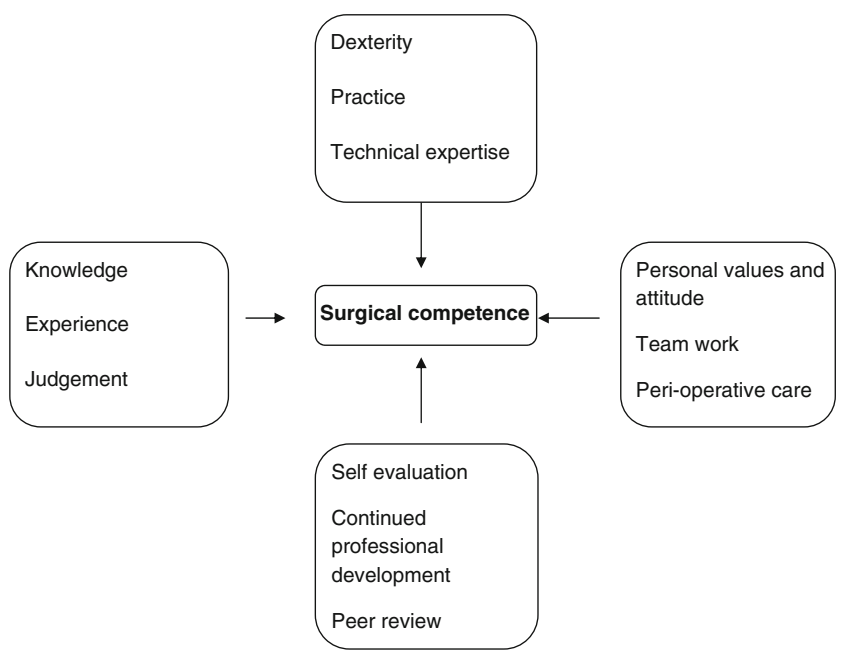

Fig. 2 Components of surgical competence

further emphasised by the anecdotal evidence that increasing medical or conservative management of patients with ectopic pregnancy reduces the opportunity for surgical training in theatre.

Knowledge base should be expanded by courses, local educational activities and web-based resources, to name a few. In this study, only $47 \%$ of the trainees had attended a suitable course within a defined time period.

In the UK, trainees are required to undergo regular objective assessment- OSATS. Implementation of this tool creates an interaction between the trainee and the supervisor, where various aspects of trainees' performance are assessed. This tool has proven its value in improving the trainees' understanding and improvement in performance [25]. The secondary effect of this tool in increasing the direct supervision and systematic discussion of trainees' performance is a key feature facilitating 'formative assessment'.

In Table 1, we have summarised the published data regarding trainee involvement in the laparoscopic management of tubal pregnancy in the UK over the last decade. It would appear from these articles that a high proportion of tubal pregnancies can be managed through the laparoscopic route. From this limited information, it is not clear how the trainee involvement is changing in the wider context. Of course, practitioners' willingness to submit their data and publication bias must be borne in mind when interpreting the wider trend.

\section{Conclusion}

Our national survey of trainees demonstrates that there is a high level of trainee engagement in laparoscopic surgery for ectopic pregnancy. Despite the variable satisfaction with the training aspects, majority anticipate attainment of competency by the end of the training period. With increasing standardisation of training, use of objective assessment tools and increasing consultant presence, we anticipate all trainees will become versed in laparoscopic surgery for ectopic pregnancy. This would be more likely to be achieved if simulators are formally integrated within the gynaecological surgery training syllabus. This will be realised once a steady state of all the necessary resources has been established.

Declaration of interest The authors report no conflicts of interest. The authors alone are responsible for the content and writing of the paper.
Table 1 Summary of UK literature regarding surgical access and trainee involvement in tubal pregnancy surgery

\begin{tabular}{lcccc}
\hline Authors & Year & No. of cases & Laparoscopy (\%) & Trainee surgeon (\%) \\
\hline Olagundoye et al. [26] & 2000 & 106 & 66 & 68 \\
Mohamed et al. [27] & 2002 & 209 & 84 & 50 \\
Davidson and Nicholson [28] & 2002 & 50 & 62 & 90 \\
Odejinmi et al. [29] & 2003 & 62 & 90 & 16 \\
Subair et al. [10] & 2004 & 40 & 64 & 53 \\
Karri and Harris [30] & 2005 & 114 & 89 & 33 \\
Odejinme et al. [8] & 2010 & 179 & 84 & 51 \\
\hline
\end{tabular}




\section{Appendix}

Laparoscopic salpingectomy questionnaire

(Questionnaire for trainees)

Circle as appropriate

1. What is your current grade? Specialist Registrar (....yr) or SpecialityTrainee (3, 4, 5, 6, 7 )

Total length of registrar training in O \& G: .yrs.........months

2. How many cases of laparoscopic salpingectomy have you been involved with in the past 12 months?

.............

3. In how many cases have you performed all or most of the procedure in the past 12 months? (i.e. level 4 or 5 ) .............

4. What is your past total experience of this procedure?

\begin{tabular}{|l|l|}
\hline \multicolumn{1}{|c|}{ LEVEL } & No \\
\hline 1 - observed & \\
\hline 2 - assisted & \\
\hline 3 - performed part of the procedure & \\
\hline 4 - performed all or most of the procedure & \\
\hline 5 - performed under indirect supervision & \\
\hline
\end{tabular}

5. What is your preferred method of excision?
(a) diathermy excision
(b) Endoloop ligature and excision

6. Do you perform salpingostomy when appropriate/feasible?
(a) yes
(b) no

7. Have you attended a laparoscopic course in the past 2 years? (RCOG level II or equivalent)

Yes No

8. Do you anticipate reaching level 5 competence on completion of CCT?

$\begin{array}{lllll}1 & 2 & 3 & 4 & 5 \\ & & & \\ & & & \text { Very }\end{array}$

Likely Likely

9. What is your level of satisfaction with training in laparoscopic salpingectomy?

$$
\begin{array}{lllll}
1 & 2 & 3 & 4 & 5
\end{array}
$$

Not satisfied

Satisfied

10. Currently do you have access to a laparoscopic simulator?

$$
\text { Yes No }
$$




\section{References}

1. Hoover KW, Tao G, Kent CK (2010) Trends in the diagnosis and treatment of ectopic pregnancy in the United States. Obstet Gynecol 115:495-502

2. Lundorff P, Thorburn J, Hahlin M, Kallfelt B, Lindblom B (1991) Laparoscopic surgery in ectopic pregnancy: a randomized trial versus laparoscopy. Acta Obstet Gynecol Scand 70:343-348

3. Murphy AA, Nager CW, Wujek JJ, Kettel LM, Torp VA, Chin HG (1992) Operative laparoscopy versus laparotomy for the management of ectopic pregnancy. Fertil Steril 57:1180-1185

4. Vermesh M, Silva P, Rosen G, Stein AL, Fossum GT, Sauer MV (1989) Management of unruptured ectopic gestation by linear salpingostomy: a prospective, randomized clinical trial of laparoscopy versus laparotomy. Obstet Gynecol 73:400-404

5. The Royal College of Obstetricians and Gynaecologists (2004) Guideline number 21: the management of tubal pregnancy. RCOG Press, London

6. Saidi SA, Butler-Manuel S, Poweel M (1998) Laparoscopic treatment of ectopic pregnancy in the UK: a nationwide survey of consultant gynaecologists. Proceedings of the 28th British Congress in Obstetrics and Gynaecology. Br J Obstet Gynaecol 105(Supplement 17):48

7. Toozs-Hobson P, Bidmead J, Khalid A, Cardozo L, Hill S (2000) Current trends in management of ectopic pregnancy in the United Kingdom. J Obstet Gynaecol 20:74-77

8. Odejinmi F, Rizzuto I, Ballard KD (2010) Potential barriers to the laparoscopic management of ectopic pregnancies: a regional U.K study. Acta Obstet Gynecol Scand 89(10):1350-1353

9. Bancroft K, Whittaker MD, Clayton RD, Garry R (1999) The availability of training in the laparoscopic management of ectopic pregnancy. Gynaecol Endos 8:85-87

10. Subair O, Omojole F, Mistry N, Morgan H (2004) Trainees and the management of ectopic pregnancy. J Obstet Gynaecol 24:811-812

11. Odejinme FO, Rizzuto MI, MacRae RE, Thakur V (2008) Changing trends in the laparoscopic management of ectopic pregnancy in a London district general hospital: 7-year experience. J Obstet Gynaecol 28:614-617

12. The Royal College of Obstetricians and Gynaecologists (2009) Trainee survey report. RCOG Press, London

13. Aggarwal R, Tully A, Grantcharov T, Larsen CR, Miskry T, Farthing A, Darzi A (2006) Virtual reality simulation training can improve technical skills during laparoscopic salpingectomy for ectopic pregnancy. BJOG 113:1382-1387

14. Lim YH, Ng SP, Ng PH, Tan AE, Jamil MA (2007) Laparoscopic salpingectomy in tubal pregnancy: prospective randomized trial using endoloop versus electrocautery. Obstet Gynaecol Res 33:855-862

15. Torkington J, Smith SG, Rees B, Darzi A (2001) The role of the basic surgical skills course in the acquisition and retention of laparoscopic skill. Surg Endosc 15:1071-1075
16. Pareek G, Hedican SP, Bishoff JT, Shichman SJ, Wolf JS Jr, Nakada SY (2008) Skills-based laparoscopy training demonstrates long-term transfer of clinical laparoscopic practice: additional follow-up. Urology 72:265-267

17. Maagaard M, Sorensen JL, Oestergaard J, Dalsgaard T, Grantcharov TP, Ottesen BS, Larsen CR (2011) Retention of laparoscopic procedural skills acquired on a virtual-reality surgical trainer. Surg Endosc 25:722-727

18. Crist DW, Gadacz TR (1993) Complications of laparoscopic surgery. Surg Clin North Am 73:265-289

19. Gadacz TR (2000) Update on laparoscopic cholecystectomy, including a clinical pathway. Surg Clin North Am 80:1127-1149

20. Seymour NE, Gallagher AG, Roman SA, O’Brien MK, Bansal VK, Andersen DK, Satava RM (2002) Virtual reality training improves operating room performance: results of a randomized, double-blinded study. Ann Surg 236:458-463

21. Grantcharov TP, Kristiansen VB, Bendix J, Bardram L, Rosenberg J, Funch-Jensen P (2004) Randomized clinical trial of virtual reality simulation for laparoscopic skills training. Br J Surg 91:146-150

22. Larsen CR, Soerensen JL, Grantcharov TP, Dalsgaard T, Schouenborg L, Ottosen C, Schroeder TV, Ottesen BS (2009) Effect of virtual reality training on laparoscopic surgery: randomised controlled trial. BMJ 338:b1802-b1808

23. Majmudar T, Slack M (2009) Laparoscopy training for obstetrics and gynaecology trainees? A pilot study in the Eastern Deanery, UK. Gynaecol Surg 6:45-50

24. Qureshi NS, Wiener JJ, Weerakkody ANA (2006) Laparoscopic management of tubal ectopic pregnancy: availability of training. Obstet Gynaecol 8:251-255

25. Lentz GM, Mandel LS, Goff BA (2005) A six-year study of surgical teaching and skills evaluation for obstetric/gynecologic residents in porcine and inanimate surgical models. Am J Obstet Gynecol 193:2056-2061

26. Olagundoye V, Adeghe J, Guirguis M, Cox C, Murphy D (2000) Laparoscopic surgical management of ectopic pregnancy: a district general hospital experience. J Obstet Gynaecol 20:620-623

27. Mohamed H, Maiti S, Phillips G (2002) Laparoscopic management of ectopic pregnancy: a 5-year experience. J Obstet Gynaecol 22:411-414

28. Davidson E, Nicholson SC (2002) Management of ectopic pregnancy in a Scottish teaching hospital: implications for training. J Obstet Gynaecol 22:197-200

29. Odejinmi F, Madhuvrata P, Naftalin A, Boulton J, Chenoy R, Raveendran M (2003) Enthusiasm and teamwork-the basis for increase in laparoscopic surgery for ectopic pregnancy: an Inner London district hospital experience. J Obstet Gynaecol 23:645-647

30. Karri K, Harris CP (2005) Successful laparoscopic management of ectopic pregnancy in a district hospital. J Obstet Gynaecol 25:769-771 